\title{
Comparison of Effects of Potassium lodide and lodosalicylates on the Antioxidant Potential and lodine Accumulation in Young Tomato Plants
}

\author{
Mariya Halka ${ }^{1}$ (D) Sylwester Smoleń ${ }^{1}$ (D) $\cdot$ Iwona Ledwożyw-Smoleń ${ }^{2}$ (D) $\cdot$ Włodzimierz Sady $^{1}$
}

Received: 7 February 2019 / Accepted: 16 May 2019 / Published online: 30 May 2019

(c) The Author(s) 2019

\begin{abstract}
Iodine (I) is classified as a beneficial element for plants. Until now, there have been only hypotheses regarding the uptakes of organic iodine compounds by plant roots. The purpose of our research was to compare the uptakes and effects of the application of the following mineral and organic iodine compounds on young tomato plants: KI, 5-iodosalicylic (5-ISA), and 3,5-diiodosalicylic (3,5-diISA) acids. An additional control combination included the treatment with salicylic acid (SA) alone. All compounds were introduced into the nutrient solution in 5, 10, 25, and $50 \mu \mathrm{M}$ I concentrations. It was established that after the application of 5-ISA and 3,5-diISA, iodine is taken up to a smaller extent than from KI. The tested KI, 3,5-diISA, and 5-ISA doses had no negative impact on the growth and development of plants, apart from the reduction of shoot biomass after the application of 3,5-diISA in 10 and $25 \mu \mathrm{M}$ I doses. All applied compounds, except for SA, caused a reduction of ascorbic acid (AA) content and increase of dehydroascorbic acid (DHA) content in leaves. A significant increase of APX activity was noted only for the highest doses of KI and 5-ISA. None of the iodine compounds, in most tested doses, have substantially increased the CAT and POX activities in tomato leaves. Application of KI decreased the levels of all analyzed sugars in tomato leaves. The effect of iodosalicylates on sugar content varied depending on the compound: when applied in the highest dose 5-ISA increased, while 3,5-diISA decreased the sugar accumulation in tomato plants. In all tested treatments, a reduction of SA content in leaves was noted. We conclude that organic iodine compounds, i.e., 3,5-diISA and 5-ISA, can be taken up by the roots of tomato plants at an early stage of development.
\end{abstract}

Keywords Iodine biofortification $\cdot$ Organic and mineral iodine $\cdot$ Iodosalicylates $\cdot$ Oxidative stress

Electronic supplementary material The online version of this article (https://doi.org/10.1007/s00344-019-09981-2) contains supplementary material, which is available to authorized users.

Sylwester Smoleń

sylwester.smolen@urk.edu.pl

Mariya Halka

mariya.halka@student.urk.edu.pl

Iwona Ledwożyw-Smoleń

iwona.ledwozyw-smolen@urk.edu.pl

Włodzimierz Sady

wlodzimierz.sady@urk.edu.pl

1 Unit of Plant Nutrition, Institute of Plant Biology and Biotechnology, Faculty of Biotechnology and Horticulture, University of Agriculture in Kraków, Al. 29 Listopada 54, 31-425 Kraków, Poland

2 Unit of Biochemistry, Institute of Plant Biology and Biotechnology, Faculty of Biotechnology and Horticulture, University of Agriculture in Kraków, Al. 29 Listopada 54, 31-425 Kraków, Poland

\section{Abbreviations}

2-IBeA 2-Iodobenzoic acid

3,5-diISA 3,5-Diiodosalicylic acid

4-IBeA 4-Iodobenzoic acid

5-ISA 5-Iodosalicylic acid

AA Ascorbic acid

APX Ascorbate peroxidase

BeA Benzoic acid

CAT Catalase

DHA Dehydroascorbic acid

KI Potassium iodide

POX Guaiacol peroxidase

ROS Reactive oxygen species

SA Salicylic acid

SABP SA-binding proteins

SAMT $\quad S$-Adenosyl-L-methionine enzyme:salicylic acid carboxyl methylotransferase

S3H Salicylic acid 3-hydroxylase

SOD Superoxide dysmutase 


\section{Introduction}

Iodine is not classified among necessary plant nutrients. However, there are numerous references to its positive effects on the growth and development of plants; therefore, it belongs to the group of 'beneficial elements for plants' (Medrano-Macías et al. 2016a; Gonzali et al. 2017). In water plants, this element plays a critical role in antioxidant metabolism (Medrano-Macías et al. 2016a). According to some authors, iodides are also among the most effective antioxidants that may react with radical oxygen species (ROS) (Venturi 2011). Iodine oxidation process has been of interest to scientists since the early 1920s, which also led to classifying this element among bioactive particles (Bray and Caulkins 1921).

Numerous research papers on the introduction of exogenous iodine in plants have confirmed its positive effect on the antioxidant capacity in a plant (Blasco et al. 2008, 2011a; Medrano-Macías et al. 2016b). Among other things, the application of inorganic iodine in the form of $\mathrm{I}^{-}$and $\mathrm{IO}_{3}^{-}$compounds in lettuce plants causes an increase of the content of phenolic compounds, ascorbic acid (Blasco et al. 2008), glutathione, as well as catalase activity, whereas the $\mathrm{IO}_{3}{ }^{-}$form also improves the activity of superoxide dismutase (SOD) and ascorbate peroxidase (APX) (Blasco et al. 2011a). The research conducted by Gupta et al. (2015) on Glycine max L. has also indicated increased activities of antioxidant enzymes such as superoxide dismutase, ascorbate peroxidase, and glutathione reductase after the application of $\mathrm{IO}_{3}{ }^{-}$in 20 , 40 , and $80 \mu \mathrm{M}$ concentrations. The correlation was also found between ROS production and iodine accumulation in plants: a higher level of ROS production leads to iodine volatilization, whereas low ROS concentration causes accumulation of this element in a plant for its later use under stress conditions (Küpper et al. 2008).

Salicylic acid (SA), is a plant growth regulator involved in various metabolic and physiological processes (Hayat et al. 2010). SA plays a crucial role in activating the antioxidant system under stress conditions. (Li et al. 2014; Janda and Ruelland 2015).

Application of exogenous SA modifies the activity of antioxidant enzymes, such as APX, POX, SOD, or CAT, in treated plants, and the obtained effect varies depending, among others, on the plant species (Krantev et al. 2008; Yusuf et al. 2008). Exogenous SA also participates in the activation of the ascorbate-glutathione cycle and increases the accumulation of glutathione (Nazar et al. 2015).

The organic iodine compounds chosen for the research [3,5-diiodosalicylic acid (abbreviation: 3,5-diISA) and 5-iodosalicylic acid (abbreviation: 5-ISA)] are derivatives of SA. Little is known as to whether iodosalicylates exert regulatory effect on crop plants similar to SA. The impacts of 3,5-diISA and 5-ISA on the antioxidant capacity of crop plants also have not yet been thoroughly studied.

This research aimed to compare the effects of KI and organoiodine compounds such as 5-ISA and 3,5-diISA on the growth, development, and antioxidant capacity of young tomato plants. The secondary purpose of the research was also to determine the iodine uptake and distribution in young tomato plants as affected by the dose of tested iodine compounds.

\section{Materials and Methods}

\section{Plant Material and Treatments}

The experiment with young tomato plants (Solanum lycopersicum L.) 'Kmicic' was conducted in a growth chamber. Tomato seeds were sown into pots filled with peat substrate and watered for 1 week. Next, tomato seedlings (four to each pot) were transferred to pots (10 $\mathrm{mm}$ diameter and volume $\left.0.5 \mathrm{dm}^{3}\right)$. At the two-leaf stage, plants were watered with $1 / 2$ Hoagland solution (nutrient solution No. 2-Hoagland and Arnon 1950) containing (ppm): N 210; K 235; Ca 200; P 31; S 64; Mg 48; B 0.5; Fe 1; Mn 0.5; Zn 0.05; Cu 0.02; Mo 0.01. After the formation of 3-4 true leaves, the plants were divided into research objects, and the introduction of tested compounds was started: (1) control (only Hoagland solution); (2) control + ethanol (Hoagland solution with $0.5 \mathrm{ml} / \mathrm{L}$ of ethanol); (3) salicylic acid (SA) (concentration: $5 \mu \mathrm{M}, 10 \mu \mathrm{M}, 25 \mu \mathrm{M}, 50 \mu \mathrm{M}$ per $1 \mathrm{~L}$ of Hoagland solution); (4) potassium iodide (KI) (concentration: $5 \mu \mathrm{M} \mathrm{I}, 10 \mu \mathrm{M} \mathrm{I}$, $25 \mu \mathrm{M} \mathrm{I}, 50 \mu \mathrm{M}$ I per $1 \mathrm{~L}$ of Hoagland solution); (5) 5-iodosalicylic acid (5-ISA) (concentration: $5 \mu \mathrm{M} \mathrm{I}, 10 \mu \mathrm{M} \mathrm{I}, 25 \mu \mathrm{M}$ I, $50 \mu \mathrm{M}$ I per $1 \mathrm{~L}$ of Hoagland solution); and (6) 3,5-diiodosalicylic acid (3,5-diISA) (concentration: $5 \mu \mathrm{M} \mathrm{I}, 10 \mu \mathrm{M}$ I, $25 \mu \mathrm{M}$ I, $50 \mu \mathrm{M}$ I per $1 \mathrm{~L}$ of Hoagland solution). Ethanol in an amount of $0.5 \mathrm{ml} / \mathrm{L}$ of Hoagland solution was added to all treatments except for control plants (treatments No. 1), because SA, 3,5-diISA and 5-ISA were diluted in $0.5 \mathrm{~mL}$ of ethanol before introducing to the Hoagland solution. The total number of applications of tested compounds was five, and the plants were treated every other day alternately with $1 / 2$ Hoagland solution without iodine compounds. The first application of the examined compounds took place 3 days after transplanting plants to pots. The last application of these compounds took place on the 12th day of plant cultivation in pots. The young tomato plants were harvested the next day after the last treatment with tested compounds.

Each treatment consisted of four replicates (pots per replication) with four plants per one replicate (4 plants per one pot) - with a total of 16 plants for each treatment. The total number of plants in the experiment was 288 . The plants 
were lightened using a 600-W high-pressure sodium lamp throughout cultivation. The photoperiod was $10 \mathrm{~h}$ of light and $14 \mathrm{~h}$ of darkness. The air temperature was $25^{\circ} \mathrm{C}$ during the day and $20{ }^{\circ} \mathrm{C}$ at night. The experiment was repeated twice.

\section{Plant Analysis}

The weights of the leaves, stems, and roots of young tomato plants during the harvesting were determined. The iodine content was determined in dry plant samples, and the antioxidant capacity of plants was assessed in fresh material immediately after harvesting.

\section{Plant Analysis in Dried Samples}

\section{lodine Content Analysis}

Fresh leaves, stems, and roots of tomato plants were dried at $50{ }^{\circ} \mathrm{C}$ in a laboratory dryer under forced air circulation and ground in variable speed rotor mill Pulverisette 14, FRITSCH using $0.5 \mathrm{~mm}$ sieve.

The iodine content in tomato plants was determined according to the following procedure: $0.5 \mathrm{~g}$ of plant sample (leaves, stems or roots), $10 \mathrm{~mL}$ of double-distilled water, and $1 \mathrm{~mL}$ of $25 \% \mathrm{TMAH}$ (tetramethylammonium hydroxide) were taken in $30 \mathrm{ml}$ falcon tubes. After mixing, the samples were incubated for $3 \mathrm{~h}$ at $70{ }^{\circ} \mathrm{C}$. After incubation, the samples were cooled to the temperature of approximately $20^{\circ} \mathrm{C}$, filled with double-distilled water to make up to $30 \mathrm{~mL}$ and mixed. The samples were then centrifuged for $15 \mathrm{~min}$ at $4500 \mathrm{rpm}, 5{ }^{\circ} \mathrm{C}$. The measurements of iodine content using ICP-OES spectrometer were conducted in the supernatant without its decanting (PN-EN 15111 2008; Smoleń et al. 2016).

\section{Plant Analysis in Fresh Samples}

\section{Ascorbic, Dehydroascorbic Acids, and APX Activity Assay in Leaves}

The analyses described in this subsection were performed only on tomato leaves as the obtained root biomass was only sufficient to perform the analysis of iodine content.

The contents of ascorbic acid (AA) and dehydroascorbic acid (DHA) in fresh leaf samples were analyzed after the homogenization of $2 \mathrm{~g}$ leaves in $8 \mathrm{~mL}$ of $2 \%$ oxalic acid. Homogenates were centrifuged for $15 \mathrm{~min}$ at $4500 \mathrm{rpm}$, $5{ }^{\circ} \mathrm{C}$. Supernatants were collected, further centrifuged for $10 \mathrm{~min}$ at 10,000 rpm, and analyzed using Beckman PA 800 Plus capillary electrophoresis (CE) system equipped with DAD detection. Capillaries of i.d. $50 \mu \mathrm{m}$, o.d. $365 \mu \mathrm{m}$, and total length of $50 \mathrm{~cm}$ (40 cm to detector) were used. The negative power supply of $-25 \mathrm{kV}$ was applied (Smoleń et al. 2016). The running buffer solution containing $30 \mathrm{mM}$ $\mathrm{NaH}_{2} \mathrm{PO}_{4}, 15 \mathrm{mM} \mathrm{Na}_{2} \mathrm{~B}_{4} \mathrm{O}_{7}$, and $0.2 \mathrm{mM} \mathrm{CTAB}(\mathrm{pH} 8.80$ ) was prepared as proposed by Zhao et al. (2011).

The content of dehydroascorbic acid (DHA) in leaves was analyzed by Dresler and Maksymiec (2013) method after addition of $50 \mathrm{mM}$ DTT (Dithiothreitol) to the supernatants after the second centrifugation. Determination of AA and DHA was performed in two independent measurements using the $\mathrm{CE}$ technique. The amount of DHA was calculated by subtracting the initial AA level from the total AA level obtained after DHA reduction (Dresler et al. 2013).

Ascorbate peroxidase (APX) activity was measured according to Nakano and Asada (1981). The enzyme extracts were prepared from $1 \mathrm{~g}$ of fresh leaf tissue homogenized with $100 \mathrm{mM}$ phosphate buffer ( $\mathrm{pH}$ 7.5) containing $1 \mathrm{mM}$ EDTA, $1 \mathrm{mM}$ ascorbic acid, and 1\% PVP-40. Homogenates were centrifuged for $15 \mathrm{~min}$ at $4500 \mathrm{rpm}, 5^{\circ} \mathrm{C}$. Supernatants were collected, and further centrifuged for $10 \mathrm{~min}$ at $10,000 \mathrm{rpm}$. Supernatants after second centrifugation were intended for further analysis.

The assay mixture for APX activity determination consisted of $50 \mathrm{mM}$ phosphate buffer, $1 \mathrm{mM}$ EDTA, $5 \mathrm{mM}$ ascorbate, enzyme extract, and $0.1 \mathrm{mM} \mathrm{H}_{2} \mathrm{O}_{2}$ as the reaction initiator. The total volume of the assay mixture was $2 \mathrm{~mL}$. APX activity was estimated by the reduction in ascorbate concentration. The absorbance was read on Hitachi Spectrophotometer at $290 \mathrm{~nm}$ continuously for $3 \mathrm{~min}$ (extinction coefficient $=2.8 \mathrm{mM}^{-1} \mathrm{~cm}^{-1}$ ). The enzyme specific activity was expressed as $\mu \mathrm{mol}$ of ascorbate oxidized $\mathrm{mg}$ protein $^{-1} \min ^{-1}$. The protein content for calculation of enzyme activity was determined according to the Lowry method with bovine serum albumin as a standard (Waterborg 2002).

\section{CAT and POX Activity Assay}

The extracts for determination of catalase (CAT) and guaiacol peroxidase (POX) activities were prepared from $1 \mathrm{~g}$ of fresh leaf tissue homogenized with $100 \mathrm{mM}$ phosphate buffer ( $\mathrm{pH}$ 7.5) containing $1 \mathrm{mM}$ EDTA and 1\% PVP-40. Homogenates were centrifuged for $15 \mathrm{~min}$ at $4500 \mathrm{rpm}$, $5{ }^{\circ} \mathrm{C}$. Supernatants were collected, further centrifuged for $10 \mathrm{~min}$ at $10,000 \mathrm{rpm}$. Supernatants after second centrifugation were set aside for further analysis.

Catalase (CAT) activity was assayed according to Beers and Sizer (1952). The assay mixture was composed of $100 \mathrm{mM}$ phosphate buffer ( $\mathrm{pH} 7.5), 200 \mathrm{mM} \mathrm{H}_{2} \mathrm{O}_{2}$, and enzyme extract. The optical density of the solution was observed at $45 \mathrm{~s}$ and $60 \mathrm{~s}$ after the addition of enzyme extract to a cuvette (wavelength was $240 \mathrm{~nm}$, extinction coefficient $\left.=39.4 \mathrm{mM}^{-1} \mathrm{~cm}^{-1}\right)$. The total volume of the mixture 
was $3 \mathrm{~mL}$. The enzyme specific activity was expressed as $\mu$ mol of $\mathrm{H}_{2} \mathrm{O}_{2}$ oxidized mg protein ${ }^{-1} \mathrm{~min}^{-1}$.

Guaiacol peroxidase (POX) activity was assayed according to Reuveni et al. (1992) with modification. The assay mixture consisted of $15 \mathrm{mM}$ phosphate buffer ( $\mathrm{pH}$ 6.5), $10 \mathrm{mM}$ guaiacol (o-metoxyphenol), enzyme extract, and $1 \mathrm{mM} \mathrm{H}_{2} \mathrm{O}_{2}$ as a reaction initiator. The total volume of the mixture was $2 \mathrm{~mL}$. The absorbance of the reaction mixture was determined at $470 \mathrm{~nm}$ using Hitachi Spectrophotometer (extinction coefficient $=26.6 \mathrm{mM}^{-1} \mathrm{~cm}^{-1}$ ). POX activity was estimated by the increase in absorbance of guaiacol at $470 \mathrm{~nm}$ for $3 \mathrm{~min}$ and was expressed as $\mu \mathrm{mol}$ of guaiacol oxidized $\mathrm{mg}$ protein ${ }^{-1} \mathrm{~min}^{-1}$.

The protein content for calculation of enzyme activity was determined according to the Lowry method with bovine serum albumin as a standard (Waterborg 2002).

\section{Determination of Soluble Sugars and Salicylic Acid Content}

The contents of glucose, fructose, sucrose, and SA were determined in extracts prepared for the assessment of CAT and POX activities. For determination of sugar content, capillary electrophoresis (PA 800 Plus system with DAD detection) was used: capillary of $\varnothing 25 \mu \mathrm{m}$ and total length of $60.5 \mathrm{~cm}(50 \mathrm{~cm}$ to detector) were used. The positive power supply of $30 \mathrm{kV}$ was applied, and the temperature of detection was $18{ }^{\circ} \mathrm{C}$. The running buffer solution consisted of $3.6 \mathrm{mM} \mathrm{Na}{ }_{2} \mathrm{HPO}_{4}$ and $0.2 \mathrm{mM} \beta$-cyclodextrin. The $\mathrm{pH}$ of buffer solution was set to 12.7 using $130 \mathrm{mM} \mathrm{NaOH}$. The sum of the contents of glucose, fructose, and sucrose was presented as the total sugar content (Smoleń et al. 2016).

In order to determine SA content, capillary electrophoresis (Capel $105 \mathrm{M}$ with UV detection) was used. The applied $75 \mu \mathrm{m}$ capillary had a total length of $30 \mathrm{~cm}$ ( $20 \mathrm{~cm}$ to detector). The detector was set at $205 \mathrm{~nm}$. The power supply of $-25 \mathrm{kV}$ was applied. The temperature of capillary was $25^{\circ} \mathrm{C}$. The running buffer solution consisted of $10 \mathrm{mM}$ Tris adjusted to $\mathrm{pH}$ 2.78 with the addition of formic acid (Coolen et al. 1998).

\section{Statistical Analysis}

All data were statistically verified using ANOVA module of Statistica 12.0 PL program at the significance level $p<0.05$. In the case of significant effects, homogenous mean groups were distinguished on the basis of Tukey test.

\section{Results}

\section{Plant Biomass}

The tested iodine compounds and SA did not cause any toxic effects on the growth and development of young tomato plants (Fig. 1). The increase in the biomass of leaves was noted only after the introduction of 5-ISA in doses ranging from 5 to $25 \mu \mathrm{M}$ I. An interesting observation is that the addition of ethanol into the nutrient solution contributed to a $27 \%$ increase of fresh weight of leaves compared to the control plants and also exceeded the values noted for treatments with 5-ISA and 3,5-diSA applications (Fig. 2a-d). The lowest SA dose $(5 \mu \mathrm{M})$ did not affect the fresh weight of leaves, stems, and roots. Application of the highest SA dose $(50 \mu \mathrm{M})$ not only caused a decrease in the stems biomass but also increased root biomass by $11.8 \%$ compared to the control plants (Fig. 2a). The root growth was also significantly improved after the application of 5-ISA in 5-25 $\mu \mathrm{M}$ I doses (Fig. 2c). The leaf, stem and root biomass of tomato plants was not modified by the application of various doses of KI (Fig. 2b). Introduction of 3,5-diISA in 5, 10, $25,50 \mu \mathrm{M}$ doses reduced stem biomass compared to control and control + ethanol plants respectively by $18.2 \%, 27.3 \%$, $32.5 \%$, and $22.1 \%$, but slightly improved the growth of root system (Fig. 2d). There was no negative effect of 3,5-diISA on leaf biomass.

\section{lodine Content in Roots, Stems and Leaves of Young Tomato Plants}

Application of KI, 5-ISA, and 3,5-diISA in all tested doses increased the accumulation of iodine in tomato leaves, stems, and roots compared to control plants (Fig. 3-results for control plants are also presented in Table S1). The highest content of iodine was noted in plants treated with $50 \mu \mathrm{M}$ I as KI (Fig. 3b). The analysis of iodine distribution in the plants treated with KI revealed that, irrespective of the applied I dose, the greatest share of total I was found in stems. The level of iodine after KI treatment varied from 52.49 to $548.76 \mathrm{mg} \mathrm{I} \mathrm{kg}^{-1}$ d.w. in leaves; from 127.91 to $1023.90 \mathrm{mg} \mathrm{I} \mathrm{kg}^{-1}$ d.w. in stems; and from 54.20 to $449.16 \mathrm{mg} \mathrm{I} \mathrm{kg}^{-1}$ d.w. in roots. For each tested dose, the levels of I accumulation in leaves and stems of KI-treated plants substantially exceeded the values noted for 5-ISA and 3,5-diISA (Fig. 3b-d). Interestingly, in plants from the combination with the highest dose of 5-ISA $(50 \mu \mathrm{M}$ I), the content of I in the roots was higher than that in plants treated with $\mathrm{KI}$ in respective I dose. For 5-25 $\mu \mathrm{M}$ I doses, the differences between KI and 5-ISA regarding I accumulation in tomato roots were rather negligible. However, in all the applied doses, I content in roots treated with 3,5-diISA was lower than that in respective KI combinations.

After the applications of 5-ISA and 3,5-diISA, the greatest share of iodine was found in the roots and its content ranged from $54.06 \mathrm{mg} \mathrm{I} \mathrm{kg}^{-1}$ d.w (for $5 \mu \mathrm{M} \mathrm{I}$ ) to $600.75 \mathrm{mg} \mathrm{I} \mathrm{kg}^{-1}$ d.w (for $50 \mu \mathrm{M} \mathrm{I}$ ) after 5-ISA treatment (Fig. 3c), and from $73.27 \mathrm{mg} \mathrm{I} \mathrm{kg}^{-1}$ d.w (for $5 \mu \mathrm{M}$ I) to $204.84 \mathrm{mg} \mathrm{I} \mathrm{kg}^{-1}$ d.w (for $50 \mu \mathrm{M} \mathrm{I}$ ) after 3,5-diISA 


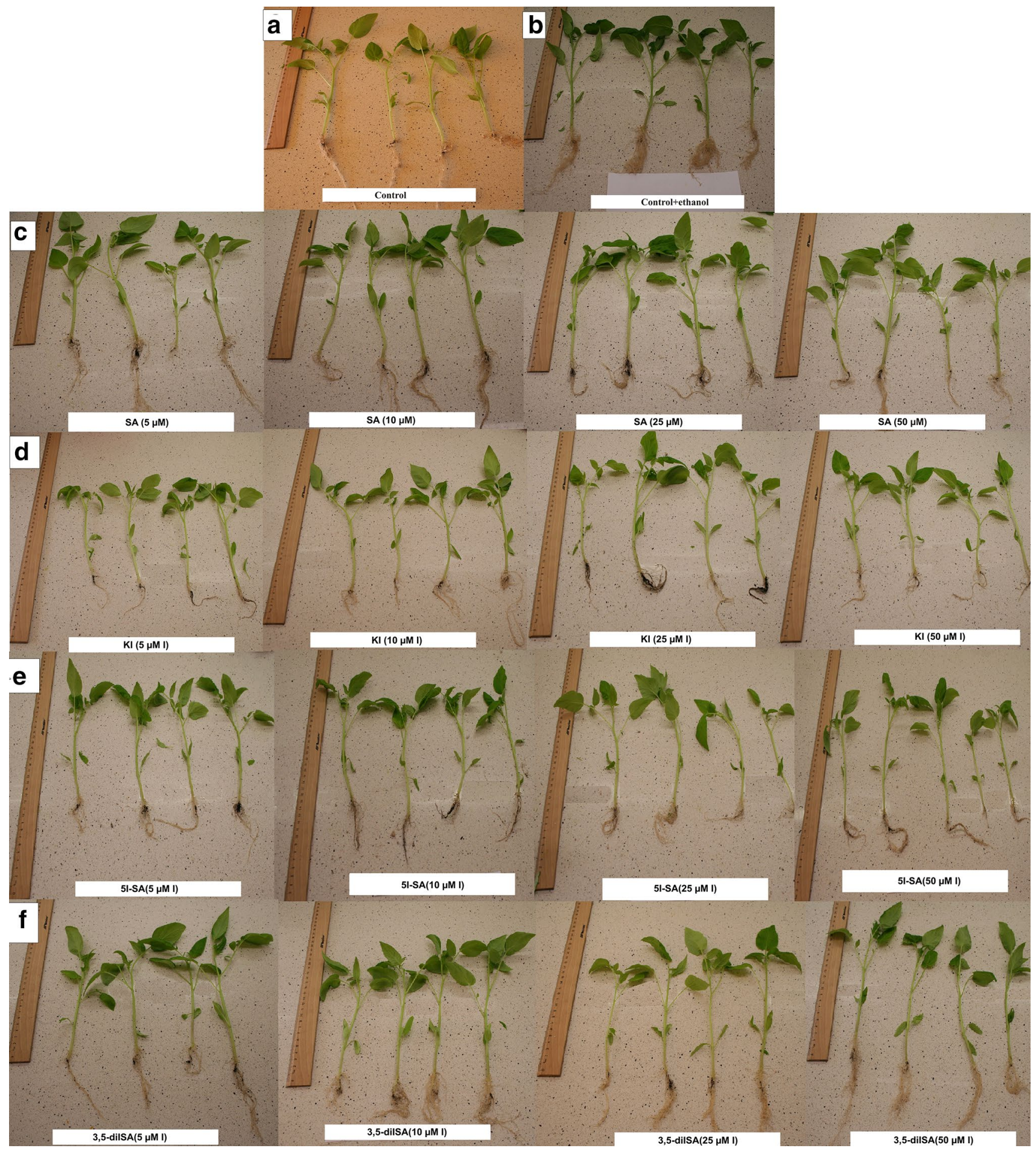

Fig. 1 Phenotypes of young tomato plants from the control (a), control+ethanol (b), after treatments with SA (c), KI (d), 5-ISA (e), and 3,5diISA (f) acids

treatment (Fig. 3d). The I contents in the leaves of plants treated with the same doses of 5-ISA and 3,5-diISA did not vary significantly. However, the application of 5-ISA increased I accumulation in shoots in relation to 3,5-diISA by $17.0 \%, 390.0 \%, 267.8 \%$, and $213.1 \%$, respectively, for
5, 10, 25, and $50 \mu \mathrm{M}$ I doses (Fig. 3c, d). The application of exogenous SA to young tomato plants did not affect iodine content in leaves, but slightly increased its levels in shoots and roots (Fig. 3a, Table S1). 


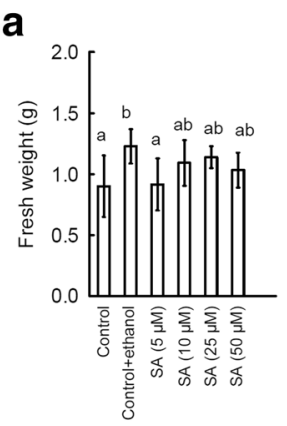

Leaves

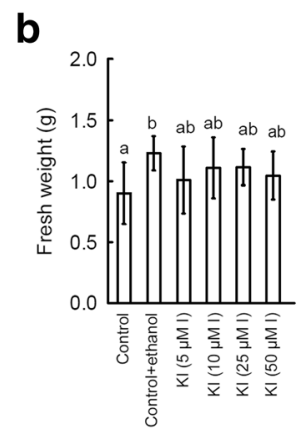

Leaves

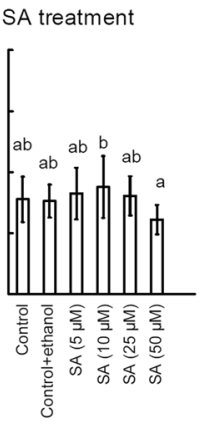

Stems

$\mathrm{KI}$ treatment

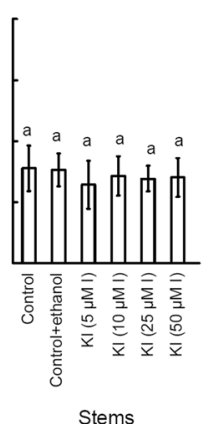

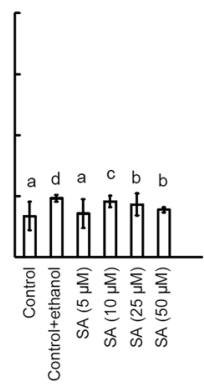

Roots

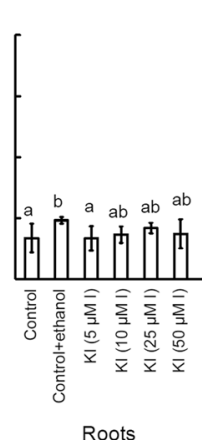

Roots

Fig. 2 Average fresh weights of leaves, stems, and roots of a single young tomato plant after treatments with salicylic (SA) (a), potassium iodide (KI) (b), 5-iodosalicylic (5-ISA) (c), and 3,5-diiodosalicylic

\section{The Content of Ascorbic and Dehydroascorbic Acids and APX Activity in Leaves}

The increase in ascorbate peroxidase (APX) activity was noted in tomato seedlings grown in the nutrient solution containing $\mathrm{KI}$ in doses of 25 and $50 \mu \mathrm{M}$ I as well as 5-ISA in a dose of $50 \mu \mathrm{M} \mathrm{I}$ (Fig. 4b, c). The highest APX activity in leaves was noted after the application of $\mathrm{KI}$ in 25 and $50 \mu \mathrm{M}$ I doses, which exceeded the value noted for the control by approximately $60 \%$ (Fig. 4 b). The application of 3,5-diISA in all doses, as well as of ethanol in the control treatment, significantly decreased the APX activity in tomato leaves. The reduction of APX activity amounted to $62.8 \%$ for control + ethanol, as well as to $43.5 \%, 54.2 \%, 48.8 \%$, and $35.9 \%$ after the application of 3,5-diISA, in 5, 10, 25, and $50 \mu \mathrm{M} \mathrm{I}$ doses, respectively (Fig. 4d).

Introduction of SA into the nutrient solution did not affect the content of AA in tomato leaves (Fig. 5a), while the application of all the tested iodine compounds reduced its level in leaves (Fig. 5b-d). The lowest AA content was noted after the application of $\mathrm{KI}$ and 3,5-diISA in $5 \mu \mathrm{M}$ I dose as well as of 5-ISA in 5 and $10 \mu \mathrm{M}$ I doses. When compared to control, this meant a reduction of AA content by $34.5 \%$ for KI, $42.8 \%$ for 3,5 -diISA, as well as $39.5 \%$ and $34 \%$ for 5-ISA (Fig. 5b-d).

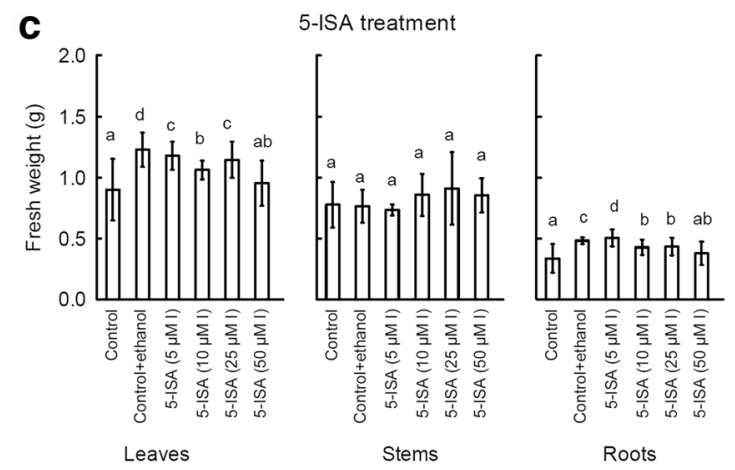

d

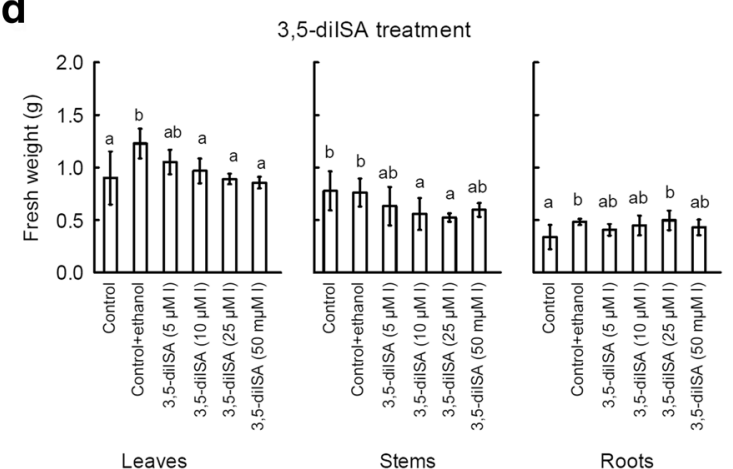

(d) acids. Means followed by the same letters are not significantly different for $p<0.05$. Bars indicate standard error $(n=8)$

The dehydroascorbic acid (DHA) content in tomato leaves was almost 10 times lower than that of AA (Figs. 5, 6). The application of all iodine compounds and SA, as well as of ethanol, caused an increase of DHA content compared to the control- except for KI applied in $50 \mu \mathrm{M}$ I dose (Fig. 5). The application of SA in doses of 25 and $50 \mu \mathrm{M}$ resulted in an almost 2.5-fold increase of DHA content in leaves (Fig. 6a). DHA contents in plant leaves treated with KI, 5-ISA and 3,5-diISA remained at a similar

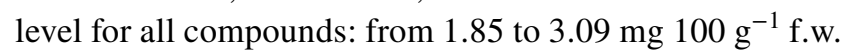
for KI, from 2.05 to $2.69 \mathrm{mg} 100 \mathrm{~g}^{-1}$ f.w. for 5-ISA, and from 2.13 to $2.74 \mathrm{mg} 100 \mathrm{~g}^{-1}$ f.w. for 3,5-diISA (Fig. 6b-d). In the case of 3,5-diISA, 10, 25, and $50 \mu \mathrm{M} \mathrm{I}$ doses of this compound caused a significant reduction of DHA content compared to $5 \mu \mathrm{M}$ I dose. With the application of $\mathrm{KI}$ in 10, $25 \mu \mathrm{M}$ I doses, the DHA content in leaves was higher than that observed after the application of the highest and the lowest doses ( 50 and $5 \mu \mathrm{M} \mathrm{I}$, respectively). In the case of 3,5-diISA $10,25,50 \mu \mathrm{M}$ I doses of this compound significantly increased DHA content in leaves compared to the control, and the level of DHA after the highest dose $(50 \mu \mathrm{M} \mathrm{I})$ application was comparable to the control with ethanol. 

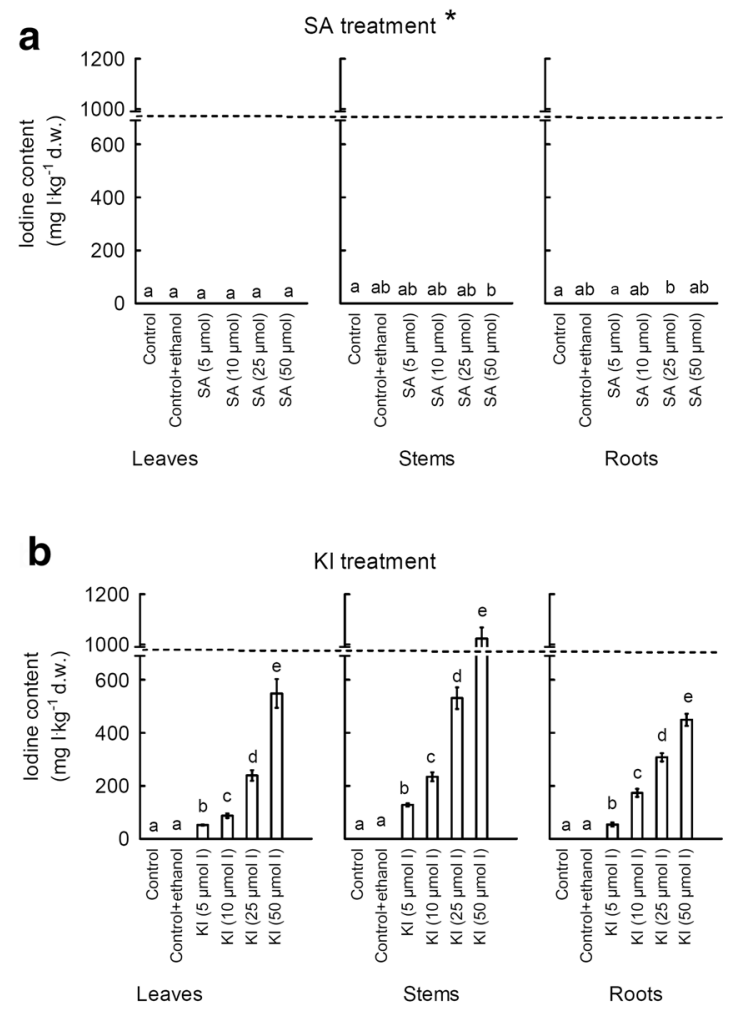

Fig. 3 Iodine contents in leaves, stems, and roots of young tomato plants after treatments with salicylic (SA) (a), potassium iodide (KI) (b), 5-iodosalicylic (5-ISA) (c), and 3,5-diiodosalicylic (d) acids. Means followed by the same letters are not significantly different for $p<0.05$. Bars indicate standard error $(n=8)$. The lines indicate

\section{Catalase and Guaiacol Peroxidase Activity}

The tested iodine compounds, as well as SA alone, modified the CAT activity in tomato leaves, and the effects varied depending on the dose (Fig. 7). Compared to control, the highest decrease of CAT activity was noted in the control object with ethanol addition. Application of 5-ISA into the nutrient solution also reduced CAT activity in tomato leaves to a comparable level for all applied doses. A similar effect was noted for 3,5-diISA applied in medium and higher doses $(10,25$, and $50 \mu \mathrm{M} \mathrm{I})$ as well as for 10 and $25 \mu \mathrm{M}$ I applied as KI (Fig. 7a, b, d).

The tested iodine compounds and SA had significant impacts on the POX activity in tomato leaves; however, the range of the modifications varied depending on the compound and its concentration (Fig. 8). The application of $5 \mu \mathrm{M}$ SA resulted in a $36.7 \%$ increase of POX activity in leaves, while for all higher doses $(10,25$, and $50 \mu \mathrm{M})$, the reduction of the POX activity was observed (Fig. 8a). The application of KI in 5, 10, and $25 \mu \mathrm{M}$ I doses caused a significant decrease of the POX activity compared to the control with no effect noted for the highest dose of

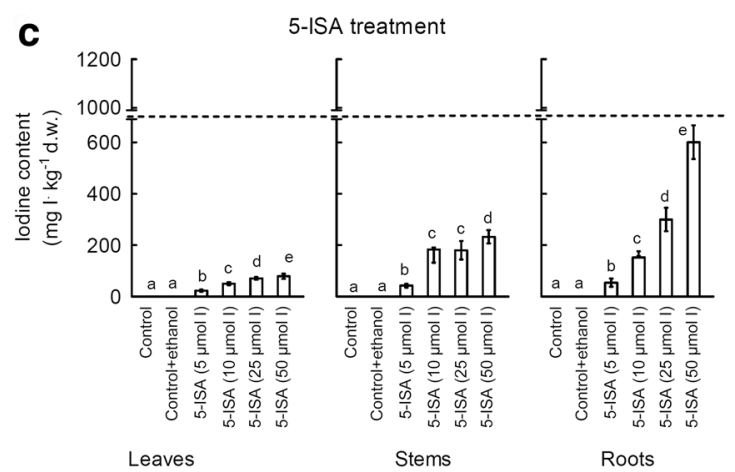

d

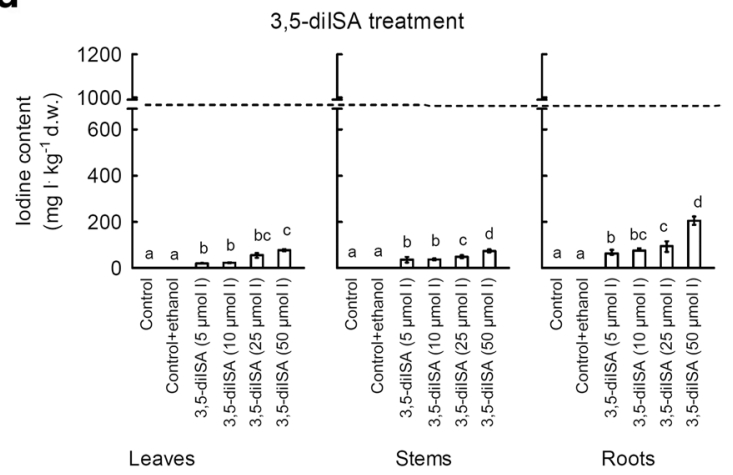

breaks in the $Y$-axis from 690 to 990 . *Due to the low content of iodine in different organs after SA treatment and in control and control+ethanol plants, the respective results are presented in Table S1 in Supplementary materials

KI (50 $\mu$ M I, Fig. 8b). Similar relations were noted in the combinations with 5-ISA application (Fig. 8c). Only the lowest dose of 3,5-diISA ( $5 \mu \mathrm{M} \mathrm{I})$ improved the POX activity in tomato leaves, and the application of 3,5-diISA in the concentrations of 10,25 , and $50 \mu \mathrm{M}$ I decreased the activity of this enzyme in tomato plants compared to that in the control (Fig. 8d).

\section{Sugar and SA Content in Leaves (Results Presented in Supplementary Materials)}

The fructose content exceeded the level of glucose and sucrose in plant leaves from all tested treatments (Figure S1, S2, and S3). In most cases, the applications of SA, KI, 5-ISA, and 3,5-diISA neither affected nor caused any significant reduction of fructose, glucose, and sucrose contents in leaves compared to the control. The observed effects of SA, 5-ISA, and 3,5-diISA on the content of analyzed sugars was not proportional to the increasing concentrations of the tested compounds in the nutrient solution. In the case of KI, all the tested iodine concentrations contributed to significant 

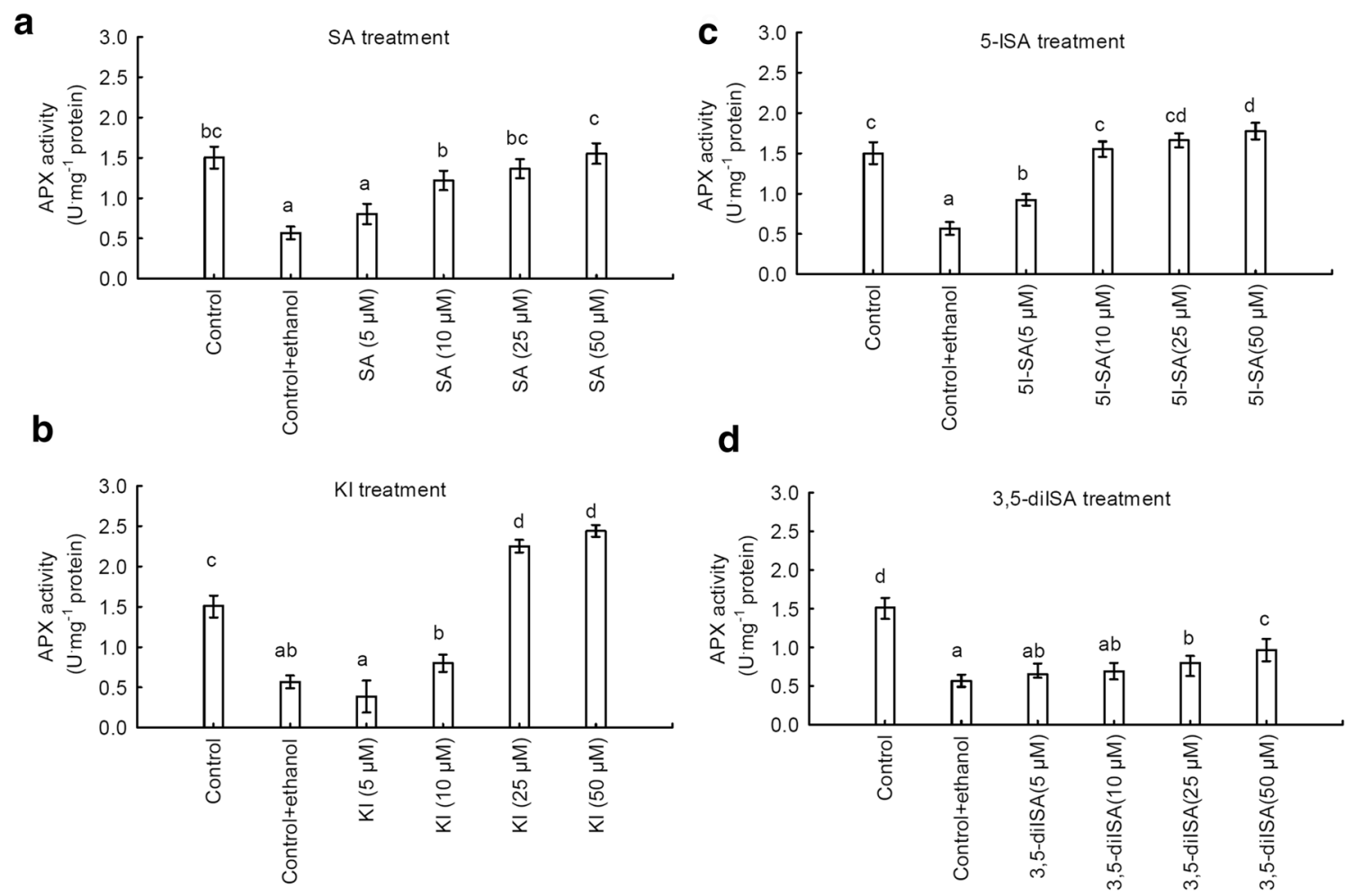

Fig. 4 Ascorbate peroxidase (APX) activity in tomato leaves after treatments with salicylic (SA) (a), potassium iodide (KI) (b), 5-iodosalicylic (5-ISA) (c), and 3,5-diiodosalicylic (3,5-diISA) (d) acids.

Means followed by the same letters are not significantly different for $p<0.05$. Bars indicate standard error $(n=8)$

Fig. 5 Ascorbic (AA) acid content in tomato leaves after treatments with salicylic (SA) (a), potassium iodide (KI) (b), 5-iodosalicylic (5-ISA) (c), and 3,5-diiodosalicylic (3,5-diISA) (d) acids. Means followed by the same letters are not significantly different for $p<0.05$. Bars indicate standard error $(n=8)$
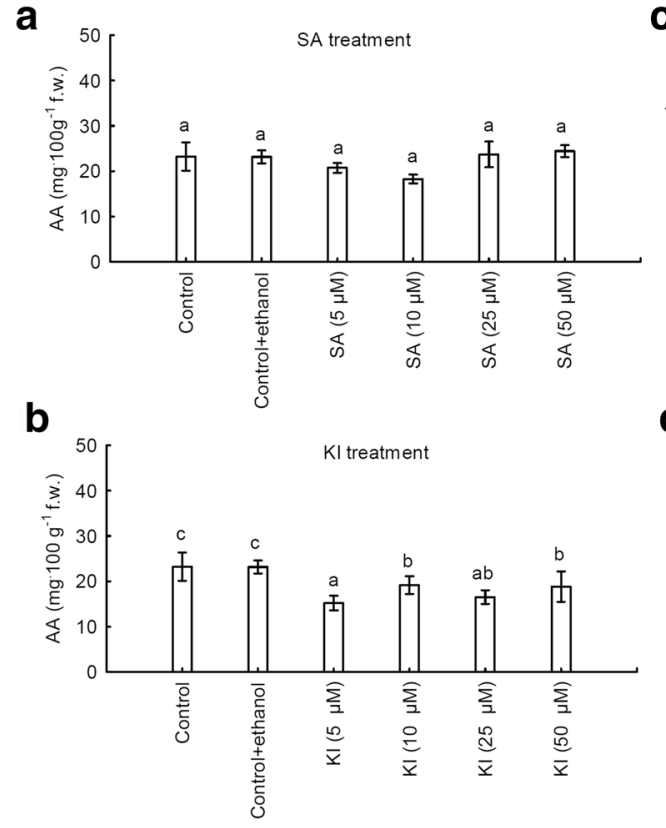
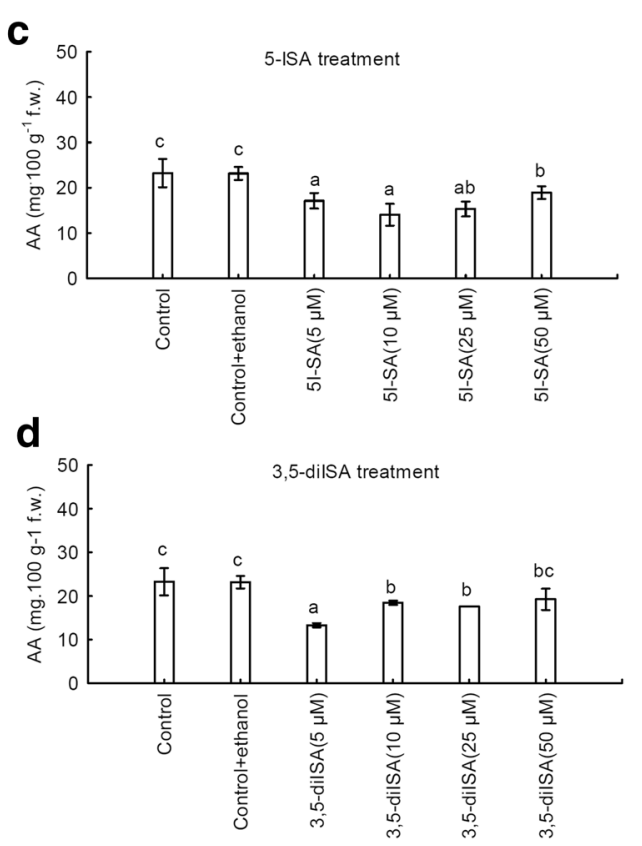

decreases of fructose, glucose, and sucrose contents in leaves-with the exception of sucrose after the application of $\mathrm{KI}$ in $25 \mu \mathrm{M}$ I dose.

Applications of all compounds (SA, KI, 5-ISA and 3,5diISA, as well as control + ethanol) in all tested doses caused a significant reduction of SA content in leaves compared to control (Figure S5). For SA, KI, and 5-ISA, the increasing doses of these compounds did not affect the range of SA content reduction. However, in the case of 3,5-diISA, the 
Fig. 6 Dehydroascorbic (DHA) acid content in tomato leaves after treatments with salicylic (SA) (a), potassium iodide (KI) (b), 5-iodosalicylic (5-ISA) (c) and 3,5-diiodosalicylic (3,5-diISA) (d) acids. Means followed by the same letters are not significantly different for $p<0.05$. Bars indicate standard error $(n=8)$

Fig. 7 Catalase (CAT) activity in tomato leaves after treatments with salicylic (SA) (a), potassium iodide (KI) (b), 5-iodosalicylic (5-ISA) (c), and 3,5-diiodosalicylic (3,5-diISA) acids (d) acids. Means followed by the same letters are not significantly different for $p<0.05$. Bars indicate standard error $(n=8)$
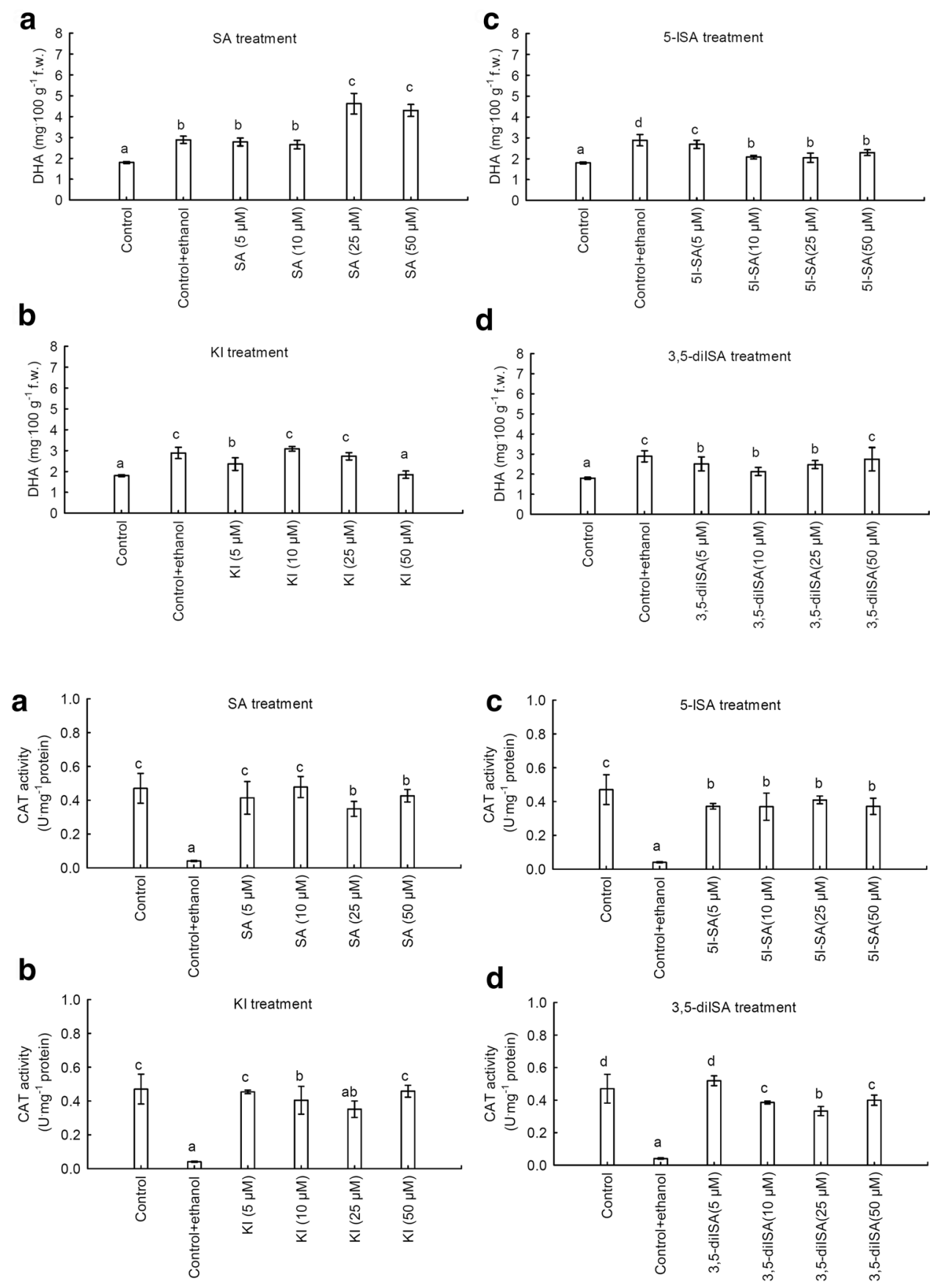

strongest decrease of SA content in leaves took place after the application of $10 \mu \mathrm{M}$ I dose.

\section{Discussion}

\section{lodine Content in Tomato Organs and its Influence on Biomass}

In the research conducted by Kiferle et al. (2013), applications of $\mathrm{KI}$ and $\mathrm{KIO}_{3}$ in iodine doses within the range of
0.5-1 mM allowed to obtain the effect of iodine biofortification of tomato fruits. At the same time, such doses were not harmful to tomato plants. Our research was conducted on tomato plants at an early stage of their growth and development, that is, in the horticultural practice, commonly used for the seedling production. Until now, the impacts of organic iodine compounds (3,5-diISA and 5-ISA) on tomato plants have not been examined in the literature analyzed by us; therefore, we applied lower iodine doses than that applied by Kiferle et al. (2013). In addition, due to its easier uptake by plants and, consequently, higher 
Fig. 8 Guaiacol peroxidase (POX) activity in tomato leaves after treatments with salicylic (SA) (a), potassium iodide (KI) (b), 5-iodosalicylic (5-ISA) (c), and 3,5-diiodosalicylic (3,5-diISA) (d) acids. Means followed by the same letters are not significantly different for $p<0.05$. Bars indicate standard error $(n=8)$
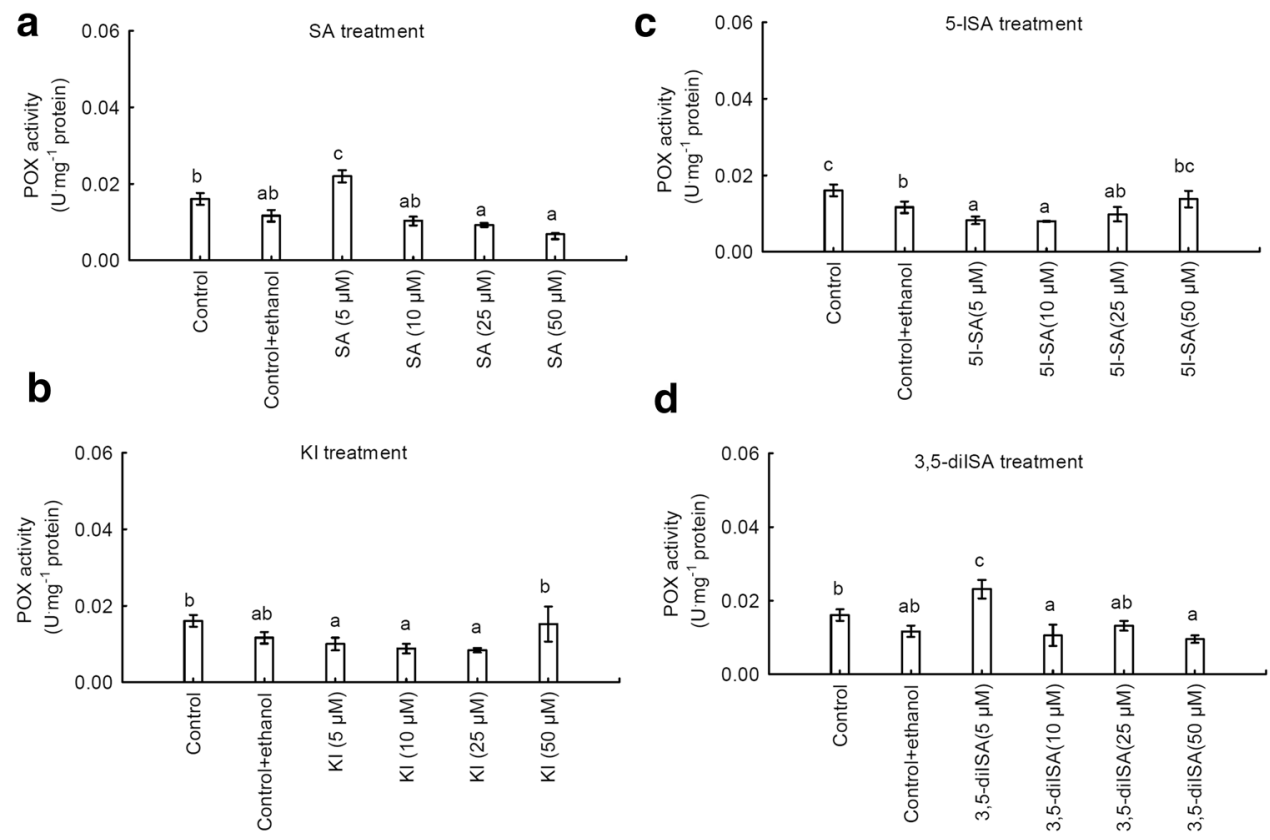

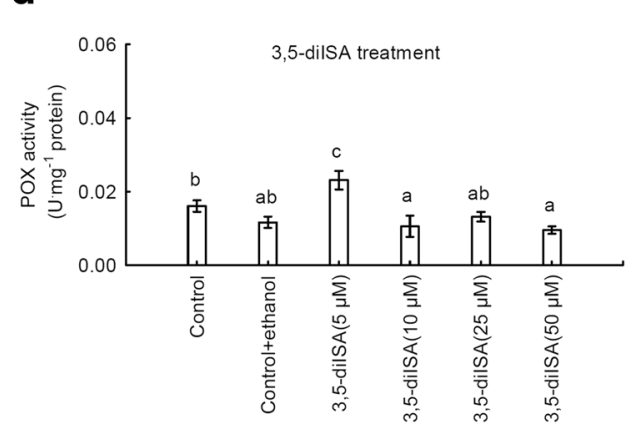

toxicity, we chose one inorganic form of iodine (KI) as a reference, (Medrano-Macías et al. 2016a). Caffagni et al. (2011) emphasize in their research on plant biofortification with iodine that in order to avoid the negative effects under greenhouse conditions, iodine in the form of $\mathrm{IO}_{3}{ }^{-}$may be introduced in $0.014 \%$ I dose, whereas in the form of $\mathrm{I}^{-}$in $0.002 \%$ I dose (Caffagni et al. 2011).

We applied SA alone as a reference compound for iodosalicylates. The obtained results confirm that iodine from iodosalicylates is indeed taken up by young tomato plants but to a smaller extent than that from KI. The research conducted by Smolen et al. (2015) not only indicates the lack of negative effect of SA, applied together with $\mathrm{KI}$ and $\mathrm{KIO}_{3}$, on tomato plants, but also underlines its positive impact, expressed, e.g., as increase in the biomass of tomato fruits and leaves, compared to the applications of $\mathrm{KI}$ and $\mathrm{KIO}_{3}$ alone. What is important, in a vast majority, the tested KI, 3,5-diISA, and 5-ISA doses did not reduce the growth and biomass of individual parts of tomato plants. The only exception was the decrease in shoot biomass after the application of 3,5-diISA in 10 and $25 \mu \mathrm{M}$ I doses.

All examined iodine compounds caused an increase of the content of this element in roots, shoots, and leaves in proportion to their doses. Iodine introduced in the form of KI was primarily accumulated in the upper part of plantsleaves and stems - whereas in the case of the application of iodosalicylates in the root system of young tomato plants. This may prove to be a more complex mechanism of uptake and transport of organic iodine compounds from leaves to roots than the other forms of iodine ions. To a large extent, this may probably depend on the simpler structure of iodide ions in comparison with iodosalicylates, which contain an aromatic ring in their structure.

\section{Ascorbate Metabolism in Young Tomato Plants}

In a plant organism, there are antioxidant protection systems, among which non-enzymatic and enzymatic systems can be distinguished. Ascorbic acid (AA), glutathione $(\mathrm{GSH})$, carotenoids, and phenolics are included in the nonenzymatic system (De Pinto and De Gara 2004). Multiple antioxidant enzymes, such as catalase (CAT), guaiacol peroxidase (POX), ascorbate peroxidase (APX) and superoxide dismutase (SOD) are classified as elements of the enzymatic system (Iba 2002).

The metabolism of ascorbic acid in plants is well recognized. One of the products of ascorbate oxidation is monodehydroascorbate radical (MDHA) which plays a key role in response to oxidation stress. MDHA is classified among the most effective ROS scavengers, due to low reactivity with oxygen, which prevents it from generating additional reactive oxygen forms (Smirnoff 2018). On the other hand, MDHA may be transformed into dehydroascorbic acid (DHA), which is a poorly stable form (Deutsch 1998). Our research demonstrated that a reduced form of AA prevailed in the leaves of young tomato plants, which is probably related to an effective reduction process of DHA. A significant decrease of AA content was noted after the application of both inorganic and organic iodine compounds, whereas no changes were noted during the application of SA alone. At the same time, an increase of DHA content in leaves was noted in plants from all treatments, compared to control (except $50 \mu \mathrm{M}$ I in $\mathrm{KI}$ form). This may prove a high level 
of oxidation of AA to MDHA, and subsequently to DHA under the influence of the tested compounds. The research conducted by Hageman et al. (1942) on tomato plants demonstrated that high KI doses (58.85 mg KI per L) caused a significant reduction of AA content in tomato fruits. Smoleń et al. (2015) revealed an increase of AA content in tomato fruits after the applications of $\mathrm{KI}$ and $\mathrm{KIO}_{3}$ and $\mathrm{KIO}_{3}+\mathrm{SA}$ into the nutrient solution with no effect exerted by simultaneous application of $\mathrm{KI}+\mathrm{SA}$.

A very important aspect of ascorbic acid metabolism is the activation of the hydrogen peroxide detoxification system in plant cells, through ascorbate peroxidase (APX), which is the key enzyme converting harmful $\mathrm{H}_{2} \mathrm{O}_{2}$ to $\mathrm{H}_{2} \mathrm{O}$ (Caverzan et al. 2012). APX has a very high affinity for $\mathrm{H}_{2} \mathrm{O}_{2}$ and may act in chloroplasts, cytosol, mitochondria, peroxisomes, as well as in apoplastic space (Sofo et al. 2015). Our research demonstrated a significant increase of APX activity in the objects with the application of KI and 5-ISA in 25 and $50 \mu \mathrm{M}$ doses. However, after the application of 3,5diISA, a decrease in the activity of this enzyme was noted in all tested doses. The research previously conducted by Medrano-Macías et al. (2016b) on tomato seedlings showed a lack of impacts of inorganic iodine $\mathrm{I}^{-}$and $\mathrm{IO}_{3}^{-}$forms on APX activity. On the other hand, the research conducted by Blasco et al. (2011a) on lettuce plants demonstrated an increase of APX activity in leaves after the application of $\mathrm{IO}_{3}{ }^{-}$form in 20,40, and $80 \mu \mathrm{M}$ doses. According to Küpper et al. (2008), iodides are capable of capturing various ROS, and as a result of oxidation stress, molecular iodine is released for the purpose of detoxification of a plant organism. This mechanism may probably serve as the explanation for the reduction of APX activity after the application of KI in 5 and $10 \mu \mathrm{M}$ I doses, whereas a higher APX activity after the application of this compound in 25 and $50 \mu \mathrm{M}$ I doses may be the effect of inducing greater antioxidation stress in young tomato plants. The reduction of APX activity in the treatments with 3,5-diISA is probably connected with the activation of other protection mechanisms against ROS, or smaller antioxidation stress in comparison with other applied compounds, i.e., SA, KI, and 5-ISA.

\section{Catalase and Guaiacol Peroxidase Activity}

Catalase (CAT) is a hydrogen peroxide $\left(\mathrm{H}_{2} \mathrm{O}_{2}\right)$ dismutase involved in the conversion of harmful $\mathrm{H}_{2} \mathrm{O}_{2}$ to $\mathrm{H}_{2} \mathrm{O}$ and $\mathrm{O}_{2}$ (Foyer and Noctor 2005). Guaiacol peroxidase (POX) participates in numerous physiological processes, such as synthesis of lignins and phenolic compounds and protective reaction of plants against ROS ( $\mathrm{Li}$ et al. 2017).

Our research showed that the applications of tested iodine compounds, as well as SA alone, may modify the activities of CAT and POX in the leaves of young tomato plants, and the effect is concentration dependent. It is considered that SA may have an inhibiting effect on CAT activity. It has been revealed that SA can bind to soluble SA-binding proteins (SABPs) with a size of $280 \mathrm{kDa}$ (Chen and Klessig 1991; Chen et al. 1993) that converts $\mathrm{H}_{2} \mathrm{O}_{2}$ to $\mathrm{H}_{2} \mathrm{O}$ and $\mathrm{O}_{2}$, i.e., exhibit a similar activity to CAT. Conrath et al. (1995) demonstrated that $1 \mathrm{mM} \mathrm{SA}$, as well as its derivatives, may limit the CAT activity in tobacco plants, both in vitro and in vivo, at the same time activating protective mechanisms against pathogens (Conrath et al. 1995). However, the effects of iododerivatives of salicylic acids such as 5-ISA and 3,5diISA have not yet been documented. The observed reduction of CAT activity may be linked to the fact that tested organic iodine compounds are SA derivatives and therefore may have affinity for SABPs, which will participate in conversion reaction of harmful $\mathrm{H}_{2} \mathrm{O}_{2}$ to $\mathrm{H}_{2} \mathrm{O}$ and $\mathrm{O}_{2}$ instead of CAT. The research on biofortification of lettuce plants with inorganic forms of iodine such as $\mathrm{I}^{-}$and $\mathrm{IO}_{3}{ }^{-}$showed an increase of CAT activity with the highest activity noted after the application of $\mathrm{IO}_{3}{ }^{-}$in $80 \mu \mathrm{M}$ dose (Blasco et al. 2011a). Gupta et al. (2015) found that the treatment with $\mathrm{IO}_{3}{ }^{-}$of soybean subjected to heavy metal stress also improved CAT activity when iodine was applied in 20 and $40 \mu \mathrm{M}$ doses. Therefore, it may be concluded that CAT activity after the introduction of iodine in a plant to a large extent depends on the chemical form of this element and plant species, including also its development stage.

The impacts of both inorganic and organic iodine compounds on POX activity are poorly recognized. In the present study, the decrease of POX activity was noted in plants treated with SA and 3,5-diISA in 10, 25, and $50 \mu \mathrm{M}$ concentrations. In the case of 5-ISA plants, the inhibition of POX activity was noted in all concentrations, whereas after the application of KI, a significant reduction of its activity was noted for 5,10 , and $25 \mu \mathrm{M} \mathrm{I}$ doses. However, many scientists demonstrated in their research an increase of POX activity after treating, e.g., wheat plants (Gholamnezhad et al. 2016), or barley leaves (Antonova Ananieva et al. 2004) with SA. The research conducted on tobacco plants by Durner and Klessig (1995) shows that SA does not cause a reduction of POX activity. However, the fact that SA may reduce the activity of horseradish peroxidase (HRP) - another representative of peroxidases-in tobacco plants is surprising. SA is considered to be a weak inhibitor of this class of enzymes, due to its lower affinity of peroxidases compared to guaiacol, pyrogallol, and hydroquinone (Durner and Klessig 1995). The decrease of POX activity in our research may also be related to other reasons, such as plant species, growing conditions, or application date of the examined compounds.

In our research, ethanol was used as the solvent for the tested organic iodine compounds. The tendency of decreasing activities of APX, CAT, and POX due to the presence of that compound in the nutrient solution was noted. In natural conditions, ethanol may be produced in fruits, seeds, and 
root tips (Cossins and Beevers 1963). The synthesis of this alcohol by plants is usually activated under stress conditions, and the measurement of ethanol content may be a stress indicator (Kimmerer and Kozlowski 1982). However, in our research, no negative impact of a relatively small addition of ethyl alcohol on the growth of plants or AA and DHA content was noted.

\section{Sugar Metabolism and SA Content in Young Tomato Plants}

Increases in the contents of glucose and fructose were found in the treatment with ethanol addition compared to the basic control. This may be linked to fast ethanol metabolism in young tomato plants. The research conducted by Cossins and Beevers (1963) on the tissues of apples, potatoes, and carrots incubated in ethanol-1- $\mathrm{C}^{14}$ demonstrated their ability to metabolize ethanol. For example, carrot tissue utilized $86 \%$ ethanol-1- $\mathrm{C}^{14}$ within $4 \mathrm{~h}$ of incubation in aerobic conditions (Cossins and Beevers 1963).

Previous research indicates that the application of inorganic iodine in the form of $\mathrm{KI}$ and $\mathrm{KIO}_{3}$ may cause changes in sugar content in plants (Blasco et al. 2011b; Smoleń et al. 2015). The $\mathrm{I}^{-}$form of iodine applied in 20,40 , and $80 \mu \mathrm{M}$ concentrations in lettuce plants increased fructose content, while in 20 and $40 \mu \mathrm{M}$ doses, it increased glucose accumulation in plants (Blasco et al. 2011b). On the other hand, in the study conducted by the same research team, the $\mathrm{IO}_{3}{ }^{-}$form did not cause any changes in the sugar content in lettuce plants. Treatment of tomato plants with KI form in $7.88 \mu \mathrm{M}$ dose caused a reduction of fructose content in fruits with no effect on the glucose accumulation in these parts of plants (Smoleń et al. 2015). In our experiment, decreases of glucose and fructose contents in tomato leaves, after the application of all tested doses of KI, as well as of sucrose content after the application in 5,10, and $50 \mu \mathrm{M}$ doses, were noted. A similar tendency of decreasing glucose and sucrose contents was noted after treating plants with 3,5-diISA, whereas the reduction of fructose content was only affected by the $50 \mu \mathrm{M}$ I dose. On the other hand, the application of 5-ISA resulted in an increase of fructose content in $50 \mu \mathrm{M}$ I dose; however, it had no impact on the glucose and sucrose contents. The fructose content exceeded the levels of glucose and sucrose in plant leaves from all tested treatments. Glucose and fructose are substrates for production of sucrose which occurs in the cytosol (Lunn and MacRae 2003); therefore, a reduction in the contents of these compounds after the application of KI and iodosalicylates also results in a reduction of sucrose content.

In our research, all compounds applied in $5-50 \mu \mathrm{M}$ concentrations caused a decrease of SA content in plant leaves; such an effect may probably be related to its metabolism to other compounds (including SA derivatives), or volatilization in the SA methylation process. Conversion of $\mathrm{SA}$ to MeSA in the latter process is regulated by $S$-adenosyl-L-methionine:salicylic acid carboxyl methyltransferase (SAMT), encoded by SAMT gene and may be induced as a protective reaction against excessive accumulation of SA in a plant (Ross et al. 1999). The previous research demonstrated that not only the application of iodosalicylates in the form of 3,5-diISA, but also of other iodine derivatives containing aromatic ring-2-iodobenzoic (2-IBeA) and 4-iodobenzoic (4-IBeA) acids-causes an increase of $S A M T$ gene expression, as well as probably also the process of SA volatilization in tomato plants in the vegetative phase of growth (Halka et al. 2018). On the other hand, 3,5-diISA may be transformed into SA sugar derivatives, as evidenced by the increase of $S 3 H$ gene expression in tomato plants (Halka et al. 2018), encoding 3-hydroxylase. The enzyme is responsible for the transformation of SA into 2,3-dihydroxybenzoic (2,3-DHBA) or 2,5-dihydroxybenzoic (2,5-DHBA) acids (Zhang et al. 2013).

\section{Conclusions}

Iodosalicylates-5-ISA and 3,5-diISA-are taken up by young tomato plants to a lesser extent than KI and are accumulated mainly in the root system of tomato plant seedlings. Probably due to the simpler structure, iodide is distributed on the upper parts of plants more easily than iodosalicylates, which contain an aromatic ring in their structure.

All the applied iodine compounds modified the APX, CAT, and POX activities, as well as glucose, fructose, and sucrose accumulations in tomato leaves. The observed effects strongly depended on the form and dose of the introduced compounds. The KI form, iodosalicylates, and SA alone caused a reduction of SA content in plants. This reduction may be associated with the transformation of this compound in the plant into other SA derivatives or with the SA methylation process as a protection mechanism against its excessive accumulation in a plant.

It can be stated that, for biofortification purposes, iodosalicylates such as 3,5-diISA and 5-ISA may potentially be applied even at the earliest stage of tomato growth.

Acknowledgements This work was supported by the Ministry of Science and Higher Education of the Republic of Poland. The organic form of iodine applied into plants was taken from our patented solution: Sady, W., Smoleń S., Ledwożyw-Smoleń, I. Methods of biofortification of vegetables with iodine. Patent No. P.410806, Polish Patent Office 20.11.2017.

\section{Compliance with Ethical Standards}

Conflict of interest The authors assure that the manuscript has not been submitted for publication elsewhere. All the authors have contrib- 
uted equally to this article, and all have agreed to submit it for publication in this journal. All the authors declare that there are no conflicts of interest to disclose.

Open Access This article is distributed under the terms of the Creative Commons Attribution 4.0 International License (http://creativeco mmons.org/licenses/by/4.0/), which permits unrestricted use, distribution, and reproduction in any medium, provided you give appropriate credit to the original author(s) and the source, provide a link to the Creative Commons license, and indicate if changes were made.

\section{References}

Antonova Ananieva E, Nikolov Christov K, Petrova Popova L (2004) Exogenous treatment with Salicylic acid leads to increased antioxidant capacity in leaves of barley plants exposed to Paraquat. J Plant Physiol 161:319-328. https://doi. org/10.1078/0176-1617-01022

Beers RF, Sizer IW (1952) A spectrophotometric method for measuring the breakdown of hydrogen peroxide by catalase. J Biol Chem 195(1):133-140

Blasco B, Rios JJ, Cervilla LM, Sánchez-Rodrigez E, Ruiz JM, Romero L (2008) Iodine biofortification and antioxidant capacity of lettuce: potential benefits for cultivation and human health. Ann Appl Biol 152:289-299. https://doi.org/10.111 1/j.1744-7348.2008.00217.x

Blasco B, Rios JJ, Leyva R, Cervilla LM, Sánchez-Rodrigez E, RubioWilhelmi MM, Ruiz JM, Romero L (2011a) Does iodine biofortification affect oxidative metabolism in lettuce plants? Biol Trace Elem Res 142:831-842. https://doi.org/10.1007/s1201 1-010-8816-9

Blasco B, Rios JJ, Leyva R, Melgarejo R, Constán-Aguilar C, SanchezRodriguez E et al (2011b) Photosynthesis and metabolism of sugars from lettuce plants (Lactuca sativa L. var. longifolia) subjected to biofortification with iodine. Plant Growth Regul 65:137-143. https://doi.org/10.1007/s10725-011-9583-0

Bray W, Caulkins A (1921) A periodic reaction in homogeneous solution and its relation to catalysis. J Am Chem Soc 43:1262-1267. https://doi.org/10.1021/ja01439a007

Caffagni A, Arru L, Meriggi P, Milc J, Perata P, Pecchioni N (2011) Iodine fortification plant screening process and accumulation in tomato fruits and potato tubers. Commun Soil Sci Plant Anal 42:706-718. https://doi.org/10.1080/00103624.2011.550372

Caverzan A, Passaia G, Rosa SB, Ribeiro CW, Lazzarotto F, MargisPinheiro M (2012) Plant responses to stresses: role of ascorbate peroxidase in the antioxidant protection. Genet Mol Biol 35:1011-1019

Chen Z, Klessig DF (1991) Identification of a soluble salicylic acidbinding protein that may function in signal transduction in the plant disease-resistance response. Proc Natl Acad Sci USA 88:8179-8183. https://doi.org/10.1073/pnas.92.10.4134

Chen Z, Ricigliano JW, Klessig DF (1993) Purification and characterization of a soluble salicylic acid-binding protein from tobacco. Proc Natl Acad Sci USA 90:9533-9537. http://www.jstor.org/ stable/2363189

Conrath U, Chen Z, Ricigliano JR, Klessig DF (1995) Two inducers of plant defense responses, 2,6-dichloroisonicotinic acid and salicylic acid, inhibit catalase activity in tobacco. Proc Natl Acad Sci USA 92:7143-7147. http://www.jstor.org/stable/2368200

Coolen SA, Huf FA, Reijenga JC (1998) Determination of free radical reaction products and metabolites of salicylic acid using capillary electrophoresis and micellar electrokinetic chromatography. J Chromatogr B 717:119-124. https://doi. org/10.1016/S0378-4347(98)00289-8

Cossins EA, Beevers H (1963) Ethanol metabolism in plant tissues. Plant Physiol 38:375-380

De Pinto MC, De Gara L (2004) Changes in the ascorbate metabolism of apoplastic and symplastic spaces are associated with cell differentiation. J Exp Bot 55:2559-2569. https://doi. org/10.1093/jxb/erh253

Deutsch JC (1998) Spontaneous hydrolysis and dehydration of dehydroascorbic acid in aqueous solution. Anal Biochem 260:223229. https://doi.org/10.1006/abio.1998.2700

Dresler S, Maksymiec W (2013) Capillary zone electrophoresis for determination of reduced and oxidised ascorbate and glutathione in roots and leaf segments of Zea mays plants exposed to $\mathrm{Cd}$ and $\mathrm{Cu}$. Acta Sci Pol Hortorum Cultus 12:143-155

Durner J, Klessig DF (1995) Inhibition of ascorbate peroxidase by salicylic acid and 2,6-dichloroisonicotinic acid, two inducers of plant defense responses. Proc Natl Acad Sci USA 92:1131211316. https://doi.org/10.1073/pnas.92.24.11312

Foyer $\mathrm{CH}$, Noctor $\mathrm{G}$ (2005) Oxidant and antioxidant signalling in plants: a re-evaluation of the concept of oxidative stress in a physiological context. Plant Cell Environ 28:1056-1071. https ://doi.org/10.1111/j.1365-3040.2005.01327.x

Gholamnezhad J, Sanjarian F, Goltapeh EM, Safaie N, Razavi K (2016) Effect of salicylic acid on enzyme activity in wheat in immediate early time after infection with Mycosphaerella graminicola. Sci Agric Biochem 47:1-8. https://doi. org/10.1515/sab-2016-0001

Gonzali S, Kiferle C, Perata P (2017) Iodine biofortification of crops: agronomic biofortification, metabolic engineering and iodine bioavailability. Curr Opin Biotechnol 44:16-26. https://doi. org/10.1016/j.copbio.2016.10.004

Gupta N, Shukla Bajpai M, Singh Majumdar R, Mishara PK (2015) Response of iodine on antioxidant levels of Glycine $\max \mathrm{L}$. grown under $\mathrm{Cd}^{2+}$ stress. Adv Biol Res 9:40-48. https://doi.org/10.5829/ idosi.abr.2015.9.1.9183

Hageman RH, Hodge ES, McHargue JS (1942) Effect of potassium iodide on the ascorbic acid content and growth of tomato plants. Plant Physiol 3:465-472. https://www.jstor.org/stable/4257628

Halka M, Klimek-Chodacka M, Smoleń S, Baranski R, LedwożywSmoleń I, Sady W (2018) Organic iodine supply affects tomato plants differently than inorganic iodine. Physiol Plant 164:290 306. https://doi.org/10.1111/ppl.12733

Hayat Q, Hayat S, Irfan M, Ahmad A (2010) Effect of exogenous salicylic acid under changing environment: a review. Environ Exp Bot 68:14-25. https://doi.org/10.1016/j.envexpbot.2009.08.005

Hoagland DR, Arnon DI (1950) The water-culture method for growing plants without soil, 2nd edn. Circular. California agricultural experiment station, 347. College of Agriculture, University of California, Berkeley

Iba K (2002) Acclimation responses to temperature stress in higher plants: approaches of gene engineering for temperature tolerance. Annu Rev Plant Biol 53:225-245. https://doi.org/10.1146/annur ev.arplant.53.100201.160729

Janda M, Ruelland E (2015) Magical mystery tour: salicylic acid signaling. Environ Exp Bot 114:117-128. https://doi.org/10.1016/j. envexpbot.2014.07.003

Kiferle C, Gonzali S, Holwerda HT, Real Ibaceta R, Perata P (2013) Tomato fruits: a good target for iodine biofortification. Front Plant Sci 4:205. https://doi.org/10.3389/fpls.2013.00205

Kimmerer T, Kozlowski TT (1982) Ethylene, ethane, acetaldehyde, and ethanol production by plants under stress. Plant Physiol 69:840 847. https://doi.org/10.1104/pp.69.4.840

Krantev A, Yordanova R, Janda T, Szalai G, Popova L (2008) Treatment with salicylic acid decreases the effect of cadmium on 
photosynthesis in maize plants. J Plant Physiol 165:920-931. https ://doi.org/10.1016/j.jplph.2006.11.014

Küpper FC, Carpenter LJ, Mcfiggans GB, Palmere CJ, Waiteh TJ, Bonebergb E, Woitisch S, Weiller M, Abela R, Grolimund D, Potin P, Butler A, Luther GW, Kroneck PMH, Mayer-Klaucke W, Feiters MC (2008) Iodide accumulation provides kelp with an inorganic antioxidant impacting atmospheric chemistry. Proc Natl Acad Sci USA 105:6954-6958. https://doi.org/10.1073/ pnas.0709959105

Li TT, Hu YY, Du XH, Tang H, Shen CH, Wu JS (2014) Salicylic acid alleviates the adverse effects of salt stress in Torreya grandis cv. Merrillii seedlings by activating photosynthesis and enhancing antioxidant systems. PloS ONE 9:e109492. https://doi. org/10.1371/journal.pone.0109492

Li R, Li D-W, Liu H-P, Hong C-L, Song M-Y, Dai Z-X, Liu J-W, Zhou J, Weng H-X (2017) Enhancing iodine content and fruit quality of pepper (Capsicum annuum L.) through biofortification. Sci Hortic 214:165-173. https://doi.org/10.1016/j.scienta.2016.11.030

Lunn JE, MacRae E (2003) New complexities in the synthesis of sucrose. Curr Opin Plant Biol 6:208-214. https://doi.org/10.1016/ S1369-5266(03)00033-5

Medrano-Macías J, Leija-Martínez P, Gonzáles-Morales S, JuárezMaldonado A, Benavidez-Mendoza A (2016a) Use of iodine to biofortify and promote growth and stress tolerance in crops. Front Plant Sci 7:1146. https://doi.org/10.3389/fpls.2016.01146

Medrano-Macías J, Leija-Martínez P, Juárez-Maldonado A, RochaEstrada A, Benavidez-Mendoza A (2016b) Effect of iodine application on antioxidants in tomato seedlings. Rev Champingo Ser Hortic 22:122-143. https://doi.org/10.5154/r.rchsh.2015.12.025

Nakano Y, Asada K (1981) Hydrogen peroxide is scavenged by ascorbate-specific peroxidase in spinach chloroplasts. Plant Cell Physiol 22:867-880. https://doi.org/10.1093/oxfordjournals.pcp. a076232

Nazar R, Umar S, Khan NA (2015) Exogenous salicylic acid improves photosynthesis and growth through increase in ascorbate-glutathione metabolism and $\mathrm{S}$ assimilation in mustard under salt stress. Plant Signal Behav 10:e1003751. https://doi. org/10.1080/15592324.2014.1003751

PN-EN15111 (2008) Food stuffs-determination of trace elementsdetermination of iodine by ICP-MS (inductively coupled plasma mass spectrometry). Polish Committee of Standardization, Warsaw (in Polish)

Reuveni R, Shimoni M, Karchi Z, Kuc J (1992) Peroxidase activity as a biochemical marker for resistance of muskmelon (Cucumis melo) to Pseudoperonospora cubensis. Phytopathology 82:749-753. https://doi.org/10.1094/Phyto-82-749
Ross JR, Nam KH, D’Auria JC, Pichersky E (1999) S-Adenosyl-L-methionine: salicylic acid carboxyl methyltransferase, an enzyme involved in floral scent production and plant defense, represents a new class of plant methyltransferases. Arch Biochem Biophys 367:9-16. https://doi.org/10.1006/abbi.1999.1255

Smirnoff N (2018) Ascorbic acid metabolism and functions: a comparison of plants and mammals. Free Radic Biol Med 122:116-129. https://doi.org/10.1016/j.freeradbiomed.2018.03.033

Smoleń S, Wierzbińska J, Sady W, Kołton A, Wiszniewska A, LiszkaSkoczylas M (2015) Iodine biofortification with additional application of salicylic acid affects yield and selected parameters of chemical composition of tomato fruits (Solanum lycopersicum L.). Sci Hortic 4:89-96. https://doi.org/10.1016/j.scienta.2015.03.023

Smoleń S, Kowalska I, Czernicka M, Halka M, Kęska K, Sady W (2016) Iodine and selenium biofortification with additional application of salicylic acid affects yield, selected molecular parameters and chemical composition of lettuce plants (Lactuca sativa L. var. capitata). Front Plant Sci 7:1553. https://doi.org/10.3389/ fpls.2016.01553

Sofo A, Scopa A, Nuzzaci M, Vitti A (2015) Ascorbate peroxidase and catalase activities and their genetic regulation in plants subjected to drought and salinity stresses. Int J Mol Sci 16:13561-13578. https://doi.org/10.3390/ijms160613561

Venturi S (2011) Evolutionary significance of iodine. Curr Chem Biol 5:155-162. https://doi.org/10.2174/187231311796765012

Waterborg JH (2002) The Lowry method for protein quantitation. In: Walker JM (ed) The protein protocols handbook. Humana Press Inc, Totowa, pp 7-10

Yusuf M, Hasan SA, Ali B, Hayat S, Fariduddin Q, Ahmad A (2008) Effect of salicylic acid on salinity induced changes in Brassica juncea. J Integr Plant Biol 50:1-4. https://doi.org/10.111 1/j.1744-7909.2008.00697.x

Zhang K, Halitschke R, Yin C, Liu C-J, Gan S-S (2013) Salicylic acid 3-hydroxylase regulates Arabidopsis leaf longevity by mediating salicylic acid catabolism. Proc Natl Acad Sci 36:14807-14812. https://doi.org/10.1073/pnas.1302702110

Zhao YQ, Zheng JP, Yang MW, Yang GD, Wu YN, Fu FF (2011) Speciation analysis of selenium in rice samples by using capillary electrophoresis-inductively coupled plasma mass spectrometry. Talanta 84:983-988. https://doi.org/10.1016/j.talanta.2011.03.004

Publisher's Note Springer Nature remains neutral with regard to jurisdictional claims in published maps and institutional affiliations. 